\title{
Preface
}

\section{Dietary protein for human health}

It is estimated by FAO that world-wide some 800 million people suffer from chronic under-nourishment as a result of insufficient food, often a basic lack of protein and energy. It is estimated that protein/energy malnutrition affects every fourth child in the world. With burgeoning world population growth, occurring particularly in the developing regions, these appalling statistics are unlikely to improve greatly, unless concerted international efforts are made to increase both the quantity and quality of food. Inadequate food leads to impaired infant growth and compromised immunity, leading in turn to disease and a cycle of ill-thrift, wasting, morbidity and premature death. The provision of foods and desired protein sources, at affordable prices, to provide a secure and varied diet, is a fundamental human right.

From a nutritional science perspective, and with respect to protein, it is necessary that we have accurate estimates of dietary protein and amino acid requirements for humans and equally are able to describe with accuracy the abilities of different foods and dietary proteins to supply amino acids to individuals of different ages and physiological states. Although, at first sight appearing to be straightforward tasks, both the estimation of amino acid requirements for humans and the quantification of dietary protein quality have proven over the years to be difficult technically. Early work in the area with adults, focussed on determining protein and amino acid intakes equating with whole body nitrogen balance (the maintenance of lean body tissue), to give defined protein requirement values. However, it is realised that dietary protein and specific amino acids may play important roles in body weight loss and the maintenance of body weight, satiety, and the attenuation of muscle loss which accompanies ageing. It is also likely that amino acids and dietary protein intake influence immune system performance, and especially when challenged by sub-clinical levels of infection. Several workers argue that the achievement of peak performance in resistance training and high intensity exercise may require higher protein intakes than the currently advised recommended daily intake. There may be a specific role for the branched chain amino acids and leucine in particular. Dietary protein intake and specific dietary amino acids may have important, and sometimes yet undiscovered, roles in maintaining optimal organ functions. Indeed, the very distinction among the definitions of 'dietary dispensable', 'dietary indispensable' and 'dietary conditionally dispensable' amino acids is becoming blurred. Consequently, 'optimal' amino acid requirements, that is those maximising long-term health outcomes and body functioning, may be quite different from 'minimal' requirements, and much more work is required to enhance our understanding of amino acid requirements for people of different ages and different health and physiological states.

Given the active on-going work on the subject of human protein metabolism and nutrition, and shifting perspectives, it was considered timely to hold an international symposium on the topic of "Dietary Protein for Human Health". Such a Symposium was organised by the Riddet Institute, Massey University, New Zealand in conjunction with Health Canada (Santé Canada) and the FAO, Rome, and was held in Auckland, New Zealand in March, 2011. The papers presented at the conference and the ensuing discussions served as a precursor to the FAO Expert Consultation on Protein Quality Evaluation also held in Auckland in late March, early April, 2011. The need for the Symposium, the following collection of papers (the Special Supplement), and the FAO Expert Consultation is given impetus by the projections of world population growth and food protein demand. There is urgency right now, to plan, to coordinate and to implement new technologies to avert what could potentially be a crisis for humanity.

This Special Supplement is a compilation of selected papers, written for the Auckland Symposium on Dietary Protein for Human Health, and forming background material for the subsequent FAO Expert Consultation. The papers are presented in three sections: The first section (pages S3-S87) focuses on background to the determination of dietary protein and amino acid requirements, amino acid scoring patterns to be used in assessing dietary protein quality and very importantly, assessment using best current knowledge and techniques, of dietary protein and amino acid adequacy in developing regions of the world. The second section (S88-S167) highlights specific metabolic roles of amino acids and discusses the concept of optimal as opposed to minimal dietary protein and amino acid requirements for sports performance, longterm health and optimal organ function. Section three (S168-S336) addresses dietary protein quality assessment and provides a comprehensive coverage of a background to protein quality assessment including regulatory aspects, an update on amino acid analytical methodologies and a detailed discussion of amino acid digestibility, availability and the Protein Digestibility Corrected Amino Acid Score (PDCAAS).

This systematic collection of original review papers makes an important and significant contribution to our understanding 
of the subject of dietary protein quality, its determination and description. The collection of papers in its entirety highlights gaps in our knowledge. In particular more work is required to undertake long-term population-based studies examining the effects of protein and amino acid intakes on health and function outcomes. The metabolic and functional roles of specific amino acids need to be further elucidated and the best practice of determining the content, digestibility and availability of amino acids in foods needs to be continually challenged, tested and refined.

\section{Dedication}

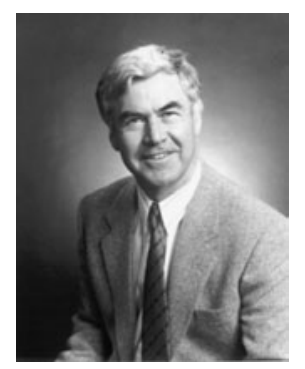

During the completion of this work we were advised, sadly, of the death of one of our colleagues and contributors, Dr Malcolm F Fuller.

Dr Fuller had a prestigious scientific career publishing some 250 scientific papers and two text books. He was a world renowned expert on mammalian protein metabolism and as applied to both farm animals and humans. Malcolm graduated MA and PhD from Trinity College, Cambridge, England and his many scientific contributions were recognised by Cambridge University by the award of Doctor of Science $(\mathrm{ScD})$, the highest earned degree awarded by a university.

This Special Supplement issue of the British Journal of Nutrition is dedicated to the memory of Dr Malcolm F Fuller.

Paul J. Moughan

Guest Editor

Riddet Institute

Massey University

New Zealand

July 2012

doi:10.1017/S0007114512003509 